Article

\title{
Enhancement of Hydrogen Productions by Accelerating Electron-Transfers of Sulfur Defects in the CuS@CuGaS 2 Heterojunction Photocatalysts
}

\author{
Namgyu Son, Jun Neoung Heo, Young-Sang Youn, Youngsoo Kim, Jeong Yeon Do* $*$ and \\ Misook Kang *(i) \\ Department of Chemistry, College of Science, Yeungnam University, Gyeongsan, Gyeongbuk 38541, Korea; \\ sng1107@naver.com (N.S.); hjn2521@naver.com (J.N.H.); ysyoun@yu.ac.kr (Y.-S.Y.); kimys6553@yu.ac.kr (Y.K.) \\ * Correspondence: daengi77@ynu.ac.kr (J.Y.D.); mskang@ynu.ac.kr (M.K.); Tel.: +82-53-810-3798 (J.Y.D.); \\ +82-53-810-2363 (M.K.); Fax: +82-53-815-5412 (M.K.)
}

Received: 29 November 2018; Accepted: 28 December 2018; Published: 4 January 2019

\begin{abstract}
CuS}$ and $\mathrm{CuGaS}_{2}$ heterojunction catalysts were used to improve hydrogen production performance by photo splitting of methanol aqueous solution in the visible region in this study. $\mathrm{CuGaS}_{2}$, which is a chalcogenide structure, can form structural defects to promote separation of electrons and holes and improve visible light absorbing ability. The optimum catalytic activity of $\mathrm{CuGaS}_{2}$ was investigated by varying the heterojunction ratio of $\mathrm{CuGaS}_{2}$ with $\mathrm{CuS}$. Physicochemical properties of $\mathrm{CuS}, \mathrm{CuGaS}_{2}$ and $\mathrm{CuS@CuGaS}$ nanoparticles were confirmed by $\mathrm{X}$-ray diffraction, ultraviolet visible spectroscopy, high-resolution transmission electron microscopy, scanning electron microscopy and energy dispersive $\mathrm{X}$-ray spectroscopy. Compared with pure $\mathrm{CuS}$, the hydrogen production performance of $\mathrm{CuGaS}_{2}$ doped with $\mathrm{Ga}$ dopant was improved by methanol photolysis, and the photoactivity of the heterogeneous CuS@CuGaS ${ }_{2}$ catalyst was increased remarkably. Moreover, the $0.5 \mathrm{CuS} @ 1.5 \mathrm{CuGaS}_{2}$ catalyst produced $3250 \mu \mathrm{mol}$ of hydrogen through photolysis of aqueous methanol solution under $10 \mathrm{~h}$ UV light irradiation. According to the intensity modulated photovoltage spectroscopy (IMVS) results, the high photoactivity of the CuS@CuGaS 2 catalyst is attributed to the inhibition of recombination between electron-hole pairs, accelerating electron-transfer by acting as a trap site at the interface between $\mathrm{CuGaS}_{2}$ structural defects and the heterojunction.
\end{abstract}

Keywords: hydrogen production; methanol photo-splitting; heterojunction; CuS@CuGaS 2 electron-hole recombination

\section{Introduction}

Copper sulfide $\left(\mathrm{Cu}_{2-x} \mathrm{~S}, 0<\mathrm{x}<1\right)$, a non-toxic and conductive chalcogen compound, has been continuously noted for its excellent photoelectric behavior, potential thermal/electrical properties, and unique biomedical properties for decades, and much extensive research on $\mathrm{Cu}_{2-x} \mathrm{~S}$ micro/nano structures is still being actively conducted. In particular, micro/nanostructured $\mathrm{Cu}_{2-x} \mathrm{~S}$ with well-controlled shapes, sizes, structures and compositions have already been applied as photocatalytic materials [1], energy conversion materials [2], biosensing materials [3], and bioimaging materials [4] and have shown reasonable results. However, comprehensive reviews of the $\mathrm{Cu}_{2-x} \mathrm{~S}$ structure in-depth in applications are still lacking. Therefore, it is necessary to categorize new functions or orientations of $\mathrm{Cu}_{2-x} \mathrm{~S}$-based nanocomposites and to develop and improve their essential elements for specific applications. Many researchers have already published a number of strategies for synthesizing 0D (dimension) , 1D, 2D, and 3D micro/nanostructures (including polyhedra) [5-7], and their efforts have made important progress in identifying $\mathrm{Cu}_{2-x} \mathrm{~S}$ micro/nanostructures. Furthermore, improved $\mathrm{Cu}_{2-x} \mathrm{~S}$ 
composites with hollow structures or super-lattices could be extended to a variety of applications in terms of performance [8]. $\mathrm{Cu}_{2-\mathrm{x}} \mathrm{S}$ belongs to the covellite mineral group with a hexagonal crystal structure, and belongs to the crystal group of P63/mmc. However, bond lengths and angles can be varied in various ways depending on the oxidation state of the copper or other anion exchanges instead of $\mathrm{S}^{2-}$ present in the surroundings. For example, $\mathrm{Cu}_{2-x} \mathrm{~S}$ is very different from $\mathrm{Cu}_{2-x} \mathrm{O}$ but shows a similar structure to $\mathrm{Cu}_{2-x}$ Se (klockmannite) [9]. CuS compound is paramagnetic due to the $3 \mathrm{~d}^{9}$ electron arrangement, and some studies have reported that all $\mathrm{Cu}$ atoms in $\mathrm{CuS}$ have an oxidation state of $\mathrm{Cu}^{+}$ based on XPS results [10]. However, it can be attributed to $\left(\mathrm{Cu}^{+}\right)_{2} \mathrm{Cu}^{2+} \mathrm{S}_{2}$ with both $\mathrm{Cu}$ (I) and $\mathrm{Cu}$ (II) in the XRD crystal structure results [11]. There are many applications of $\mathrm{Cu}_{2-\mathrm{x}} \mathrm{S}$ as a photocatalyst, among which Saranya et al. suggested that the morphology of CuS was influenced by the reaction time and surfactant, and its photocatalytic activity for decolorization of methylene blue (MB) dye under visible-light irradiation was $87 \%$ [12]. However, $\mathrm{CuS}$ is mainly used in combination with other types of photocatalysts rather than alone $[13,14]$. On the other hand, substitution of $\mathrm{Cu}_{2-x} \mathrm{~S}$ with other metal ions instead of $\mathrm{Cu}$ (II) can produce a complex crystal structure with varying performance. For example, $\mathrm{CuInS}_{2}$ and $\mathrm{CuGaS}_{2}$, which are called CIS or CIGS, are used as light absorbers in thin film solar cells; they absorb visible light in a wide area and are stable to light, unlike $\mathrm{Cu}_{2-x} \mathrm{~S}$. In particular, Salak et al. reported that $\mathrm{CuM}^{3+} \mathrm{S}_{2}$, a chalcogen compound, formed $\mathrm{Cu}$ defects on tetrahedrons and facilitated the separation of electrons and holes, which could maintain photoactivity for a long time [15]. Yue et al. concluded that $\mathrm{CuInS}_{2}$ was most sensitive at $500 \mathrm{~nm}$ with an optimal apparent quantum yield of $23.85 \%$ [16]. Han et al. found that with an increase in the reaction temperature, the excitonic absorption peaks and band gap emission peaks were systematically red-shifted, thus exhibiting a quantum confinement effect, and the $\mathrm{CuGaS}_{2}$ quantum dots showed promising visible-light-driven photocatalytic activity during degradation of rhodamine 6G [17]. We have already confirmed in previous studies that the CuS@CuInS $2: \operatorname{In}_{2} S_{3}$ catalyst has the ability to decompose water to produce hydrogen with high efficiency. Especially, it was found that the $\mathrm{CuInS}_{2}$ layer inserted between $\mathrm{CuS}$ and $\mathrm{In}_{2} \mathrm{~S}_{3}$ acts as an electron-rich interface to accelerate the reduction of water in this layer [18]. Furthermore, we have also found in previous studies that Ga has excellent performance in decomposing methanol to produce hydrogen, and that the hydrogen reverse-spillover phenomenon of Ga has a great influence on the removal of hydrogen from methanol [19]. Despite many previous studies, the excellent photosensitivity of chalcogen compounds, including $\mathrm{Cu}_{2-x} \mathrm{~S}$, in multifunctional complexes is broadly applicable to a wide range of photochemical reactions, so research on chalcogen compounds remains of interest. In particular, if chalcogen compounds are expected to perform well in the photoreaction for hydrogen production from water decomposition and their photostability is guaranteed for a long time, development of the chalcogen photocatalyst will be quite a desirable area of study for the next generation of environmentally friendly energy sources.

Therefore, in this study, we applied two particles of $\mathrm{CuS}$ and $\mathrm{CuGaS}_{2}$ as base catalysts and applied them to hydrogen production from water degradation by hetero-connecting them between two particles. The effect of the pure structure or heterojunction structure of the two particles on photoactivity was investigated. Five types of catalysts were prepared: $\mathrm{CuS}, \mathrm{CuGaS}_{2}$, 1.0CuS@1.0 $\mathrm{CuGaS}_{2}, 0.5 \mathrm{CuS} @ 1.5 \mathrm{CuGaS}_{2}$, and 1.5CuS@0.5CuGaS 2 . The molar ratios of the two particles at the heterojunction were CuS: $\mathrm{CuGaS}_{2}=1: 1,0.5: 1.5$, and 1.5:0.5, respectively, to determine which particles most influence catalytic activity.

\section{Results and Discussion}

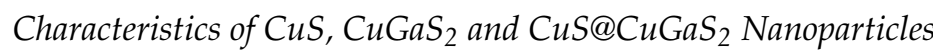

The XRD patterns (A) and high-resolution TEM (HRTEM) images (B) are shown in Figure 1 to

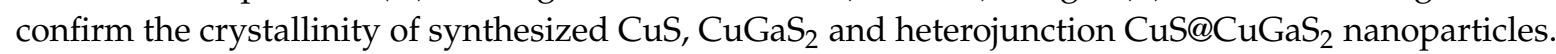
The main XRD peaks of CuS were observed at $2 \theta=27.65^{\circ}(101), 29.25^{\circ}(102), 31.75^{\circ}(103), 32.77^{\circ}$ (006), $38.77^{\circ}(105), 47.89^{\circ}(110), 52.61^{\circ}(108), 59.24(116), 73.87^{\circ}(208)$ and $78.96^{\circ}(213)$ and were 
assigned to the covellite CuS of the hexagonal crystal structure (P63 / mmc space group, JCPDS card No. 01-078-0876) [20]. On the other hand, the peaks at $31.74^{\circ}$ and $46.11^{\circ}$ correspond to $\mathrm{Cu}_{2} \mathrm{~S}$ (JCPDS card no. 00-053-0522) of cubic crystal structure, meaning that the two structures are finely mixed [21]. The XRD patterns of the $\mathrm{CuGaS}_{2}$ nanoparticle showed a $\mathrm{CuGaS}_{2}$ peak with a tetragonal crystal structure (I-42d space group, JCPDS card no. 01-085-1574) [22], although CuS was mixed. The main XRD peaks of $\mathrm{CuGaS}_{2}$ were assigned to $2 \theta=29.11^{\circ}$ (112), $33.49^{\circ}$ (200), $48.63^{\circ}$ (204) and $57.20^{\circ}$ (312). Meanwhile, the XRD pattern of the heterojunction $\mathrm{CuS@CuGaS_{2 }}$ nanoparticles was very similar to the $\mathrm{XRD}$ pattern of the $\mathrm{CuGaS}_{2}$ corresponding to the shell, but there was a slight difference in the intensity and position of the peaks as the ratio of $\mathrm{CuS}: \mathrm{CuGaS}_{2}$ varied. In particular, in the 0.5CuS@1.5 $\mathrm{CuGaS}_{2}$ sample, the peak corresponding to the (112) crystal plane migrated at a higher angle than $\mathrm{CuGaS}_{2}$. This is probably due to the small ionic radius of $\mathrm{Ga}^{3+}$ ions compared to $\mathrm{Cu}^{2+}[23]$, and it is expected that lattice parameters will be reduced according to Bragg's law [24], $n \lambda=2 \mathrm{~d} \sin$ $(\theta)$ (where $\mathrm{n}$ is the order of reflection; the wavelength of the X-rays, $\mathrm{d}=$ the distance between two layers of the crystals, and $\theta=$ the angle of the incident light). It can be expected that lattice defects are formed as compared with pure $\mathrm{CuS}$ or $\mathrm{CuGaS}_{2}$, since $\mathrm{Ga}^{2+}$ ions can be incorporated into the $\mathrm{CuS}$ lattice or the lattice gap in the process of heterojunction. This can act as an active site of the catalyst and enhance catalyst performance. Figure 1B) shows the high-resolution TEM (HRTEM) (a), the selected area electron diffraction (SAED) (b), and the elemental mapping image (c) of the heterojunction 0.5CuS@1.5 $\mathrm{CuGaS}_{2}$ particles. This result not only shows the overall shape of the particles, but also explains the intrinsic crystal structure of the particles based on the lattice parameter values in relation to the XRD results. The $0.5 \mathrm{CuS} @ 1.5 \mathrm{CuGaS}_{2}$ particles are shown in polycrystalline form as aggregates of single crystals with different orientations, which are evidenced by the lattice images and the SAED patterns. In general, when a certain point in a SAED pattern is clearly marked, it signifies a single crystal, and when a continuous ring is drawn, it signifies a polycrystalline. Therefore, heterojunction 0.5 CuS@1.5 $\mathrm{CuGaS}_{2}$ particles appeared to be polycrystalline, and lattice patterns of $\mathrm{CuS}$ and $\mathrm{CuGaS}_{2}$ were observed. We can expect $\mathrm{CuS}$ and $\mathrm{CuGaS}_{2}$ to be bonded as shown by the difference in shading in the TEM image. A lattice corresponding to $0.288 \mathrm{~nm}$ (103 diffraction plane) and $0.305 \mathrm{~nm}$ (102 diffraction plane) of CuS was observed in the bright portion, and a lattice pattern of $0.266 \mathrm{~nm}$ (200 diffraction plane) and $0.188 \mathrm{~nm}$ (204 diffraction plane) of $\mathrm{CuGaS}_{2}$ was observed in dark areas. In particular, the 200 diffraction plane of $\mathrm{CuGaS}_{2}$ has a very distinct lattice pattern, and a clear diffraction spot was also observed in the SAED pattern. This is consistent with the XRD results of the heterojunction $0.5 \mathrm{CuS} @ 1.5 \mathrm{CuGaS}_{2}$ particles and demonstrates that the particle is a continuous polycrystalline structure with a ring pattern with partially defined diffraction spots. On the other hand, the element mapping (c) results show that the $\mathrm{Cu}, \mathrm{Ga}$ and $\mathrm{S}$ elements are uniformly distributed in the $0.5 \mathrm{CuS} @ 1.5 \mathrm{CuGaS}_{2}$ particles, thus demonstrating the microstructure and composition of the heterogeneous bonded particles. 
A) XRD patterns of catalysts

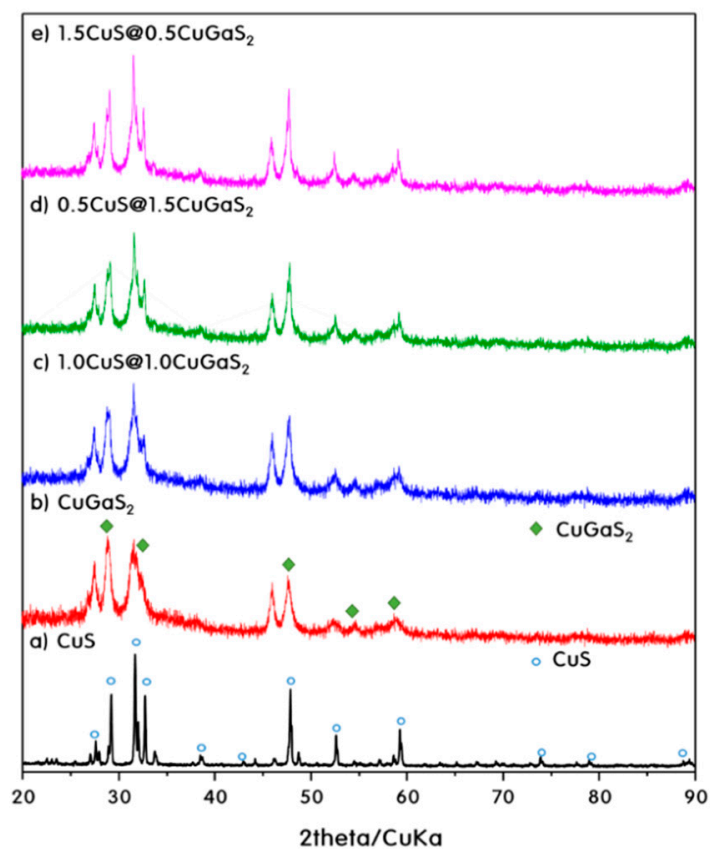

B) HRTEM images of 0.5 CuS@1.5CuGaS ${ }_{2}$ catalyst
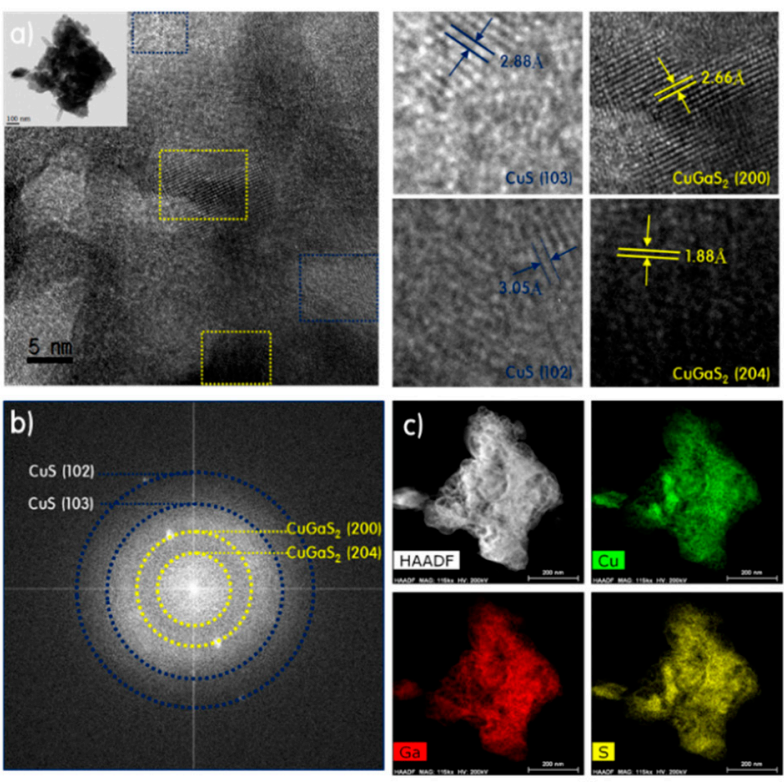

Figure 1. X-ray diffraction (XRD) patterns (A) and high-resolution transmission electron microscopy (HRTEM) images (B) of prepared samples.

Figure 2 shows the scanning electron microscope (SEM) image and energy-dispersive X-ray spectroscopy (EDS) analysis of synthesized $\mathrm{CuS}, \mathrm{CuGaS}_{2}$, and heterojunction $\mathrm{CuS} @ \mathrm{CuGaS} \mathrm{C}_{2}$ nanoparticles, showing the composition of the components present on the surface of the particles. Figure 2A shows a SEM image of each sample, showing significant aggregation between the particles in the $\mathrm{CuGaS}_{2}$ sample compared to CuS. On the other hand, the heterojunction CuS@CuGaS 2 sample inhibited the agglomeration of particles and the particle size became smaller. Figure 2B shows the EDS spectra of each sample and the atomic composition ratios are shown in the Table 1. Determination of the atomic ratio of the main metal species in the catalyst is very important because it relates to the density of the crystal lattice defects [25]. CuS and $\mathrm{CuGaS}_{2}$, heterojunction CuS@CuGaS 2 particles show that $\mathrm{Cu}, \mathrm{Ga}$ and $\mathrm{S}$ atomic components are precisely contained, and no other components are included. The atomic composition of pure $\mathrm{CuS}$ is close to the ideal stoichiometric mole fraction with a $\mathrm{Cu}: \mathrm{S}$ ratio of 46.74:53.26. The composition of the $\mathrm{CuGaS}_{2}$ sample was 31.46:27.26:41.27 with a $\mathrm{Cu}: \mathrm{Ga}: \mathrm{S}$ ratio slightly different from the stoichiometric ratio, but this can be predicted as a limitation of the EDS surface methodology. In addition, the heterojunction $\mathrm{CuS@CuGaS} 2$ samples had a relatively low proportion of $\mathrm{Ga}$. It is also expected that the difference in the sizes of $\mathrm{Cu}$ and $\mathrm{Ga}$ ions causes $\mathrm{Ga}$ to enter into the lattice of the crystal structure to reduce the amount of $\mathrm{Ga}$ exposed on the surface. Taking these factors into account, the overall molar ratio of $\mathrm{Cu}$ to $\mathrm{Ga}, \mathrm{S}$ was almost quantitatively and reliably obtained. 
A)
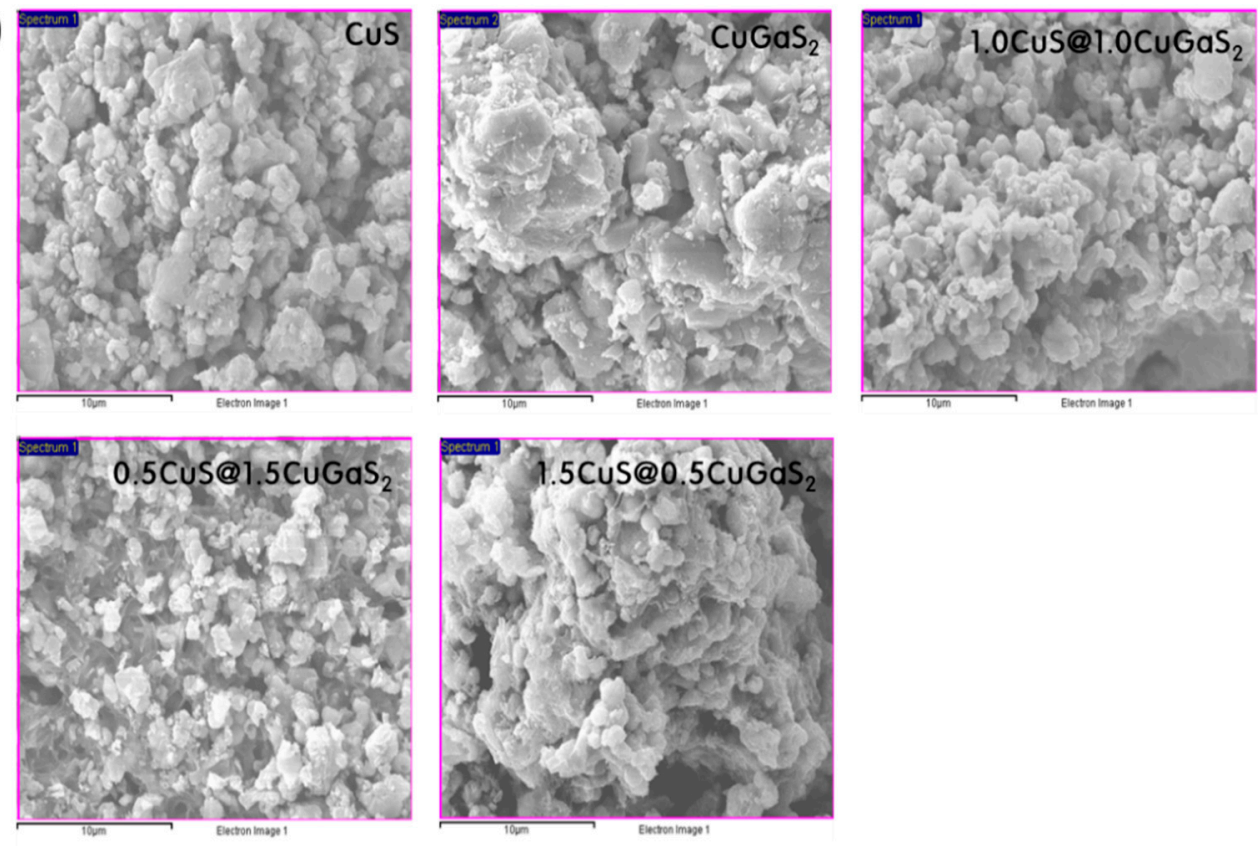

B)
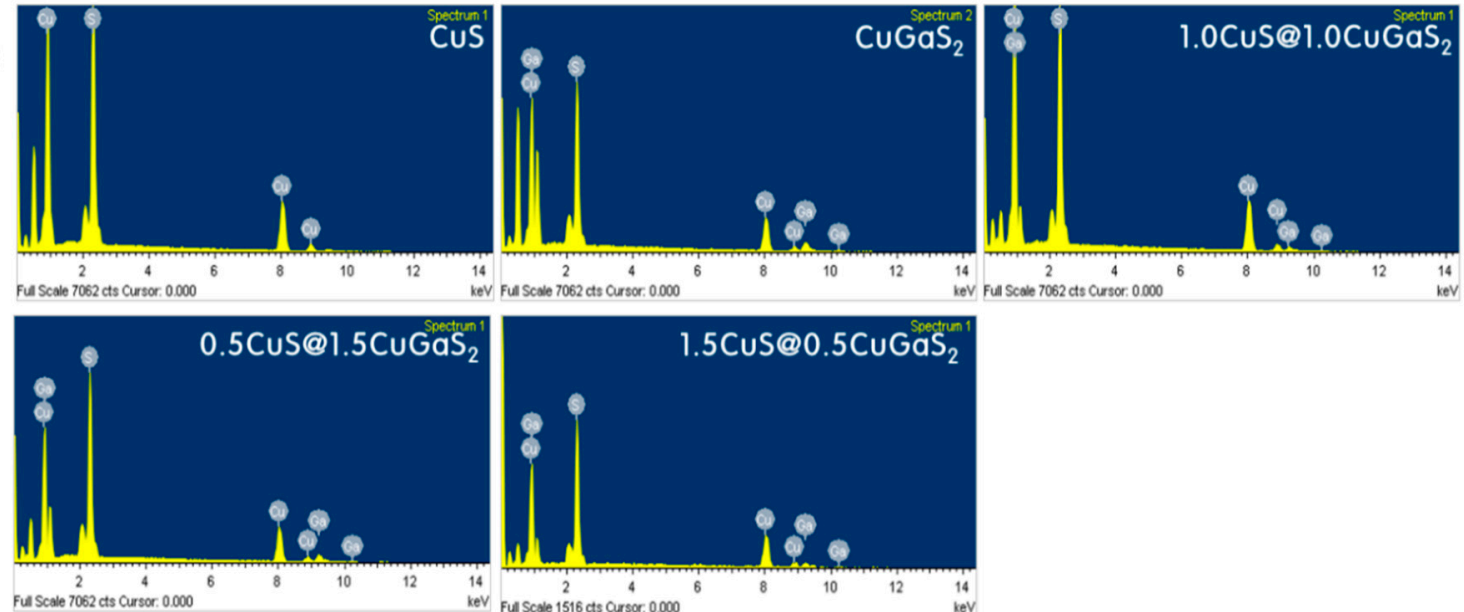

Figure 2. The SEM images (A) and energy-dispersive X-ray spectroscopy curves (B) of the CuS, $\mathrm{CuGaS}_{2}$ and CuS@CuGaS 2 catalysts.

Table 1. Atomic compositions of the $\mathrm{CuS}, \mathrm{CuGaS}_{2}$ and $\mathrm{CuS} @ \mathrm{CuGaS}_{2}$ catalysts determined by EDS.

\begin{tabular}{cccc}
\hline Catalysts/Elements & $\mathbf{C u}$ & Ga & S \\
\hline $\mathrm{CuS}$ & 46.74 & - & 53.26 \\
$\mathrm{CuGaS}$ & 31.46 & 27.26 & 41.27 \\
1.0CuS@1.0CuGaS $_{2}$ & 32.99 & 23.06 & 43.95 \\
0.5CuS@1.5CuGaS & 15.00 & 36.58 & 48.43 \\
1.5CuS@0.5CuGaS & 41.05 & 18.31 & 40.64 \\
\hline
\end{tabular}

Figure 3 shows the UV-visible reflectance spectra of the synthesized $\mathrm{CuS}, \mathrm{CuGaS}_{2}$ and heterojunction CuS@CuGaS 2 nanoparticles. UV-visible absorption spectroscopy is widely used to investigate microscopic changes caused by the chemical characteristics of the surface of the particles [26], and the optical band gap can be calculated through absorption spectra. Figure 3A clearly shows that the $\mathrm{CuS}, \mathrm{CuGaS}_{2}$ and heterojunction CuS@CuGaS 2 samples show absorption spectra in the region of 300 800 nm, and CuS in particular exhibited a pronounced absorption shoulder at about $620 \mathrm{~nm}$. In the $\mathrm{CuGaS}_{2}$ and $\mathrm{CuS@CuGaS}$ samples, the apparent absorption shoulder peak 
disappeared, but the overall absorption range was similar to CuS. These results suggest that $\mathrm{CuS}$, $\mathrm{CuGaS}_{2}$ and $\mathrm{CuS} @ \mathrm{CuGaS}_{2}$ samples can be used as promising photocatalytic materials to absorb visible light. Based on the absorption spectrum, the band gap was calculated by the Tauc equation [27], $\alpha \mathrm{h} v=\mathrm{A}\left(\mathrm{h} v=\mathrm{E}_{\mathrm{g}}\right)^{\mathrm{n}}$. Where $\mathrm{h} v$ is the photon energy, $\alpha$ is the absorption coefficient, $\mathrm{A}$ is the constant relative material, and $\mathrm{n}$ is the value that depends on the transitional nature ( 2 is direct allowed transition, 2/3 is direct suppressed transition, 2/3 is indirectly permissible transition). In addition, the energy band gap can be predicted from the wavelength extrapolated from the exciton peak called $\lambda_{1 / 2}$, or the point where the end of the absorption curve meets the $x$ axis. The band gaps of pure CuS samples and $\mathrm{CuGaS}_{2}$ were 1.63 and $2.34 \mathrm{eV}$, respectively. This value is similar to the band gap reported in other papers [28]. The bandgap of the heterojunction 0.5CuS@1.5 $\mathrm{CuGaS}_{2}$ particles was $2.32 \mathrm{eV}$. As $\mathrm{CuGaS}_{2}$, which has a longer band gap, is bonded to $\mathrm{CuS}, \mathrm{CuGaS}_{2}$ first acts as a photosensitizer, and excited electrons can be transferred to CuS. If the bandgap is long, the recombination between the photogenerated electrons and the hole pair is delayed, and the photoactivity can be increased.

A) UV/Vis spectra

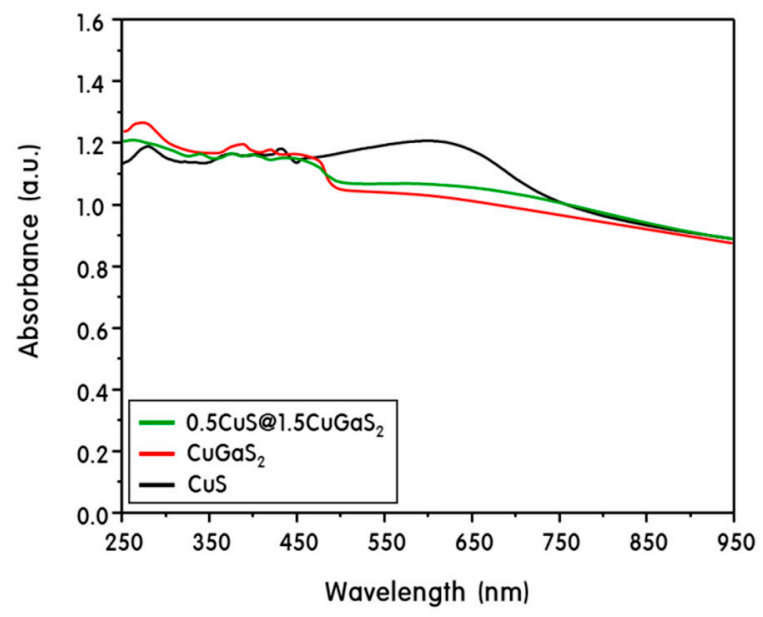

Figure 3. UV-visible spectroscopy curves CuS@CuGaS 2 catalysts.
B) Tauc plots

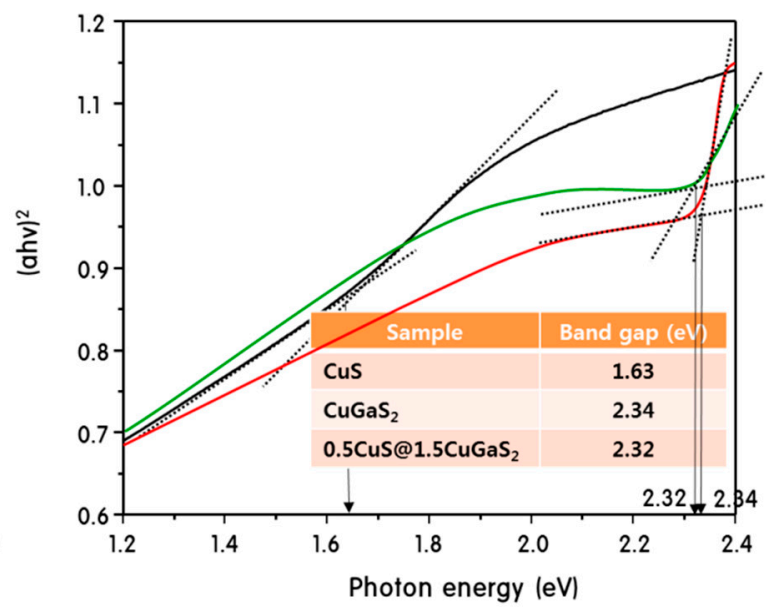

(A) and Tauc plots (B) of CuS, $\mathrm{CuGaS}_{2}$ and

In general, the behavior of photogenerated carriers is closely related to photocatalytic activity. The generation, separation, transport and recombination of photogenerated electron-hole pairs have a great influence on photocatalytic activity [29]. Therefore, the photocurrent measurement and the photoluminescence measurement results are shown in Figure 4 in order to understand the separation efficiency and recombination characteristics of the photogenerated electrons and hole pairs. Figure 4A shows the results of measuring the photocurrent value when the light was irradiated by controlling the switch of the light source at intervals of $30 \mathrm{~s}$. Electrons were excited by the irradiated light to generate excited electron and hole pairs. Their separation efficiency and mobility are closely related to the photocurrent value [30]. The photocurrent density values were increased in the order of $\mathrm{CuS}$ $<1.5 \mathrm{CuS} 0.5 \mathrm{CuGaS}_{2}<\mathrm{CuGaS}_{2}<1.0 \mathrm{CuS} @ 1.0 \mathrm{CuGaS}_{2}<0.5 \mathrm{CuS} @ 1.5 \mathrm{CuGaS}_{2}$. The pure CuS catalyst showed only a slight tendency for photocurrent density to drop momentarily when the light was turned off. In general photocurrent results, the photogenerated holes migrate to the catalyst surface and are captured or trapped by the reduced species in the electrolyte, and the electrons undergo backside contact through the catalyst, leading to an increase in the initial anodic photocurrent. Then, after the competitive separation of the electron and hole pairs and the equilibrium of the recombination, the photocurrent is kept constant, while the CuS temporarily decreases the photocurrent. This is presumably due to the fact that the traced holes on the catalyst surface are not captured or trapped by the reduced species in the electrolyte, but instead are competitively recombined with the electrons in 
the conduction band of the catalyst [31]. On the other hand, the photocurrent density of $\mathrm{CuGaS}_{2}$ and heterojunction CuS@CuGaS 2 catalysts was not only increased, but also showed excellent stability and reliability. It is believed that the addition of the Ga dopant induces more exciton formation and that structural or surface defects caused by heterojunction act as capture sites, or accelerate electron-transfer, resulting in more efficient photogenerated charge separation.

\section{A) Photocurrent response results}

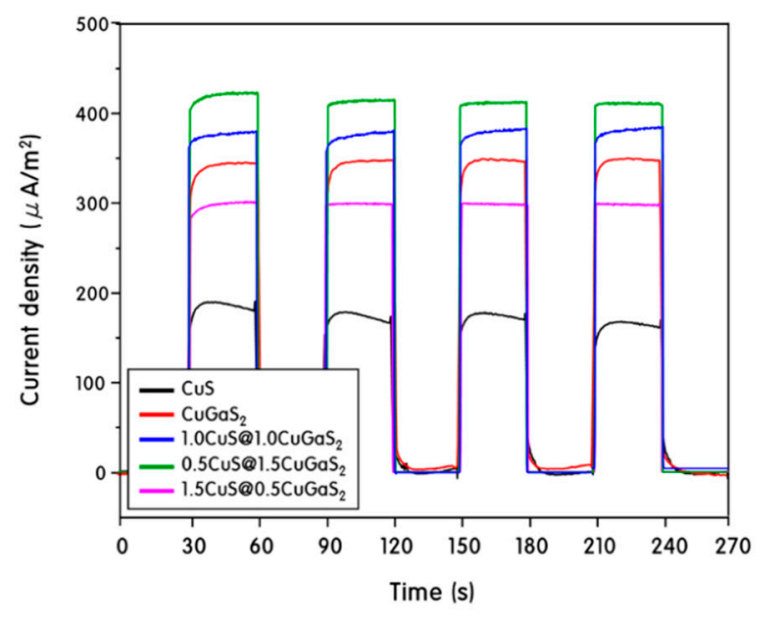

\section{B) Photoluminescence spectra}

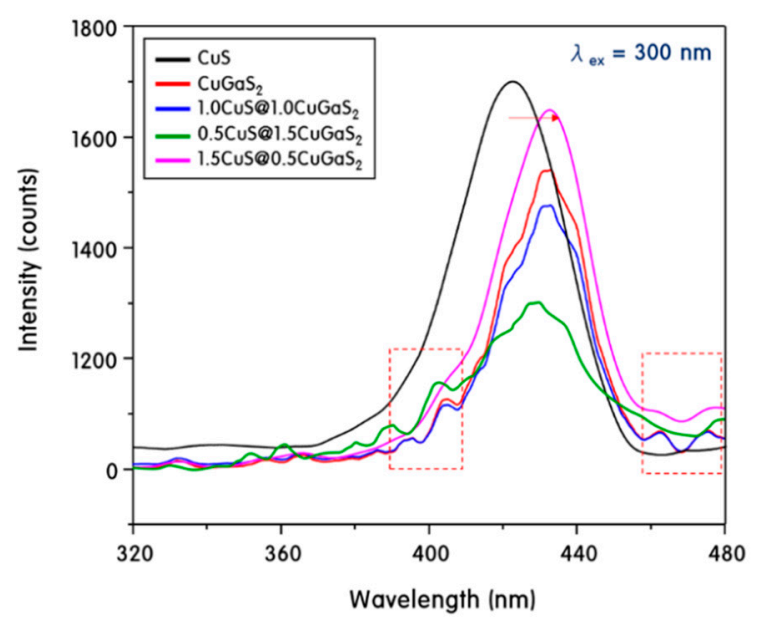

Figure 4. Photocurrent responses (A) and photoluminescence spectra (B) of CuS, $\mathrm{CuGaS}_{2}$ and CuS@CuGaS 2 catalysts.

The transfer process of the photogenerated charge carrier is closely related to photoluminescence, and the photoluminescence measurement results are shown in Figure 4B. The position and intensity of the emission peak of photoluminescence (PL) differs depending on the kind of the catalyst and the vacancy [32]. Generally, as the intensity is increased, the recombination of the photogenerated electron and the hole pair is promoted and the photocatalytic activity is decreased [33]. When an excitation wavelength of $300 \mathrm{~nm}$ was irradiated, an emission peak was observed at about $420 \mathrm{~nm}$ in all of the $\mathrm{CuS}, \mathrm{CuGaS}_{2}$ and heterojunction $\mathrm{CuS@CuGaS}$, nanoparticles. Especially, when Ga was added, the photoluminescence peak intensity of $\mathrm{CuGaS}_{2}$ and the heterogeneous $\mathrm{CuS} @ \mathrm{CuGaS}{ }_{2}$ catalyst was slightly shifted to the long wavelength side. As the number of defect lattices generated in the Ga doping and heterojunction process increases, the electron trap site increases, which results in suppression of the recombination of photogenerated electrons and hole pairs. On the other hand, $\mathrm{CuGaS}_{2}$ and heterojunction $\mathrm{CuS} @ \mathrm{CuGaS}_{2}$ catalysts to which Ga was added, in comparison with pure $\mathrm{CuS}$, had new emission peaks near $400 \mathrm{~nm}$ and $480 \mathrm{~nm}$. According to Mehmood et al. [34], the blue emission peak at around $400 \mathrm{~nm}$ is due to a high energy defect due to the dopant. In addition, the electrons trapped by the dopant cannot generate excitons because they are bound by surface oxygen defects and other defects, thereby reducing the overall PL intensity. The blue-green emission peak at about $480 \mathrm{~nm}$ corresponds to the radiative transition of an electron to the deep donor level of the metal interstitials to an acceptor level of neutral $\mathrm{V}_{\text {metal }}$ [35]. In contrast to photocurrent measurement, the photoluminescence intensity decreased in the order of CuS $>1.5 \mathrm{CuS} 0.5 \mathrm{CuGaS}_{2}>\mathrm{CuGaS}_{2}>$ 1.0CuS@1.0CuGaS $>0.5 \mathrm{CuS} @ 1.5 \mathrm{CuGaS}_{2}$. As a result, the heterojunction 0.5CuS@1.5CuGaS 2 catalyst showed the lowest photoluminescence intensity, and the Ga doping and heterojunction structure can play an important role in increasing the light efficiency by slowing the recombination between exciton and hole pairs the most.

Based on the results of photoluminescence measurements, further intensity modulated photovoltage spectroscopy (IMVS) measurements were performed to compare the excited electron recombination lifetime for $\mathrm{CuS}, \mathrm{CuGaS}_{2}$ and heterojunction $\mathrm{CuS} @ \mathrm{CuGaS}_{2}$ catalysts, and the results are shown in Figure 5A. IMVS is a useful method to study lifetime of electrons, which relates to 
the electron recombination process [36]. The IMVS plot (A) of all samples showed a semicircular shape, and the larger the size of the semicircle in the IMVS results, the longer the recombination lifetime [37]. The electron recombination lifetime (B) was calculated from the IMVS plot using the equation [38] $\mathrm{sr}=1 / 2 \pi \mathrm{f}_{\min }$, where $\mathrm{f}_{\min }$ is the frequency of the minimum imaginary component of the plot. As with the results of the photoluminescence measurement, the electron recombination lifetime increased in the order of: $\mathrm{CuS}<\mathrm{CuGaS}_{2}<\mathrm{CuS@CuGaS}{ }_{2}$. The increased IMVS electron lifetime indicates that the residence time at the electron trap site increases. Figure $5 \mathrm{~B}$ shows that $\mathrm{CuGaS}_{2}$ increases the recombination lifetime due to the effect of Ga dopant compared to CuS, but shows the longest recombination life when the two catalysts are hetero-bonded. These results indicate that defects or catalyst surfaces formed during the heterojunction process generate more trap sites, and that the electron recombination lifetime is accelerated while accelerating electron-transfer, which may exert an excellent photocatalytic activity.

A-a) IMVS curves of CuS

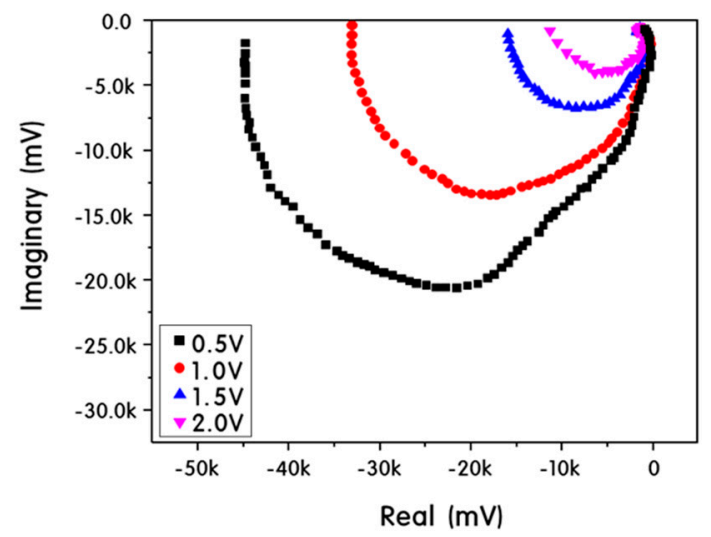

A-c) IMVS curves of 0.5 CuS@1.5CuGaS 2

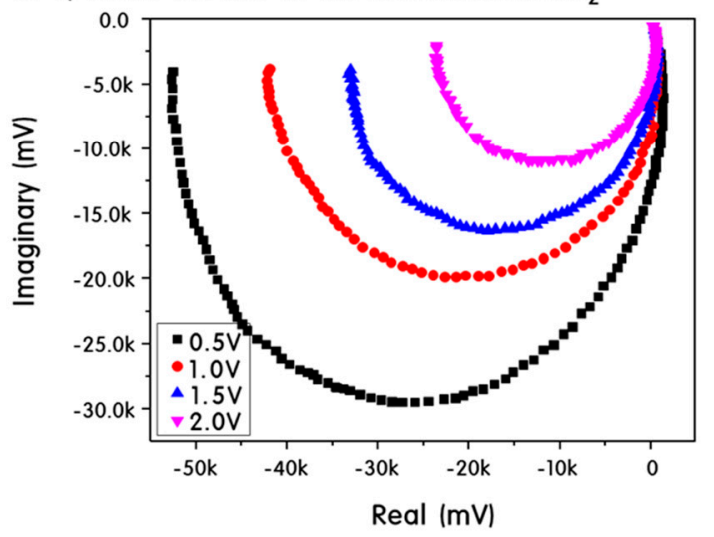

A-b) IMVS curves of CuGaS

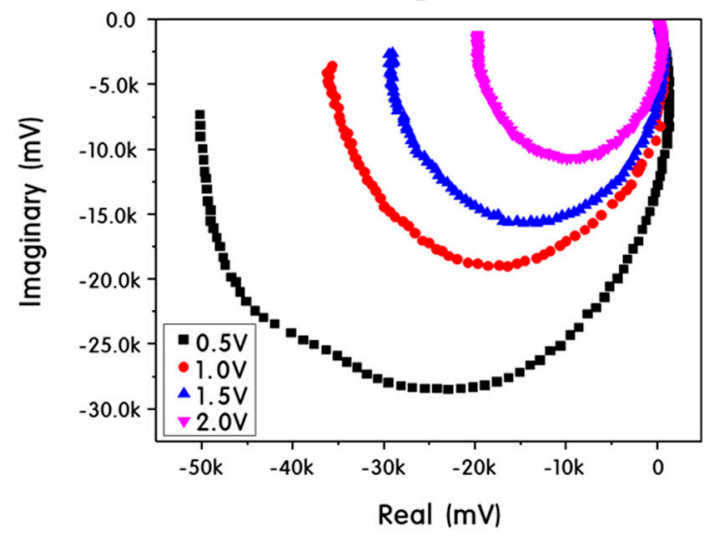

B) Recombination lifetime plot

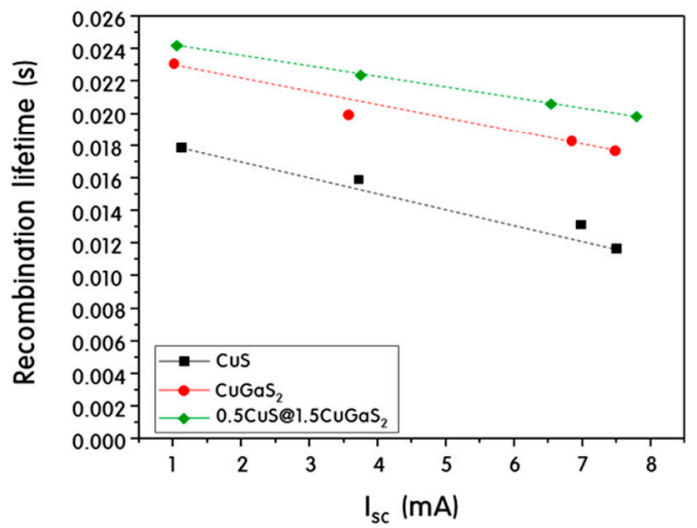

Figure 5. Intensity modulated photovoltage spectroscopy (IMVS) curves (A) and electron recombination lifetime (B) of $\mathrm{CuS}, \mathrm{CuGaS}_{2}$ and $\mathrm{CuS@CuGaS}$ catalysts.

XPS was measured to investigate the chemical states of $\mathrm{Cu}, \mathrm{Ga}$ and $\mathrm{S}$ ions in the surface state of the heterojunction 0.5CuS@1.5CuGaS 2 sample. The results are shown in Figure 6. In Cu atomic spectra, peaks corresponding to $\mathrm{Cu} 2 \mathrm{p}_{3 / 2}$ and $2 \mathrm{p}_{1 / 2}$ were observed at 934.27 and $953.71 \mathrm{eV}$. A typical satellite peak of the $\mathrm{Cu}^{2+}$ oxidation state was observed at 942.78 and $963.06 \mathrm{eV}$, except for these two distinct peaks, indicating a defect in $\mathrm{Cu}^{2+}$. This implies a vacancy in the surface state that occurs in vacancies or $0.5 \mathrm{CuS} @ 1.5 \mathrm{CuGaS}_{2}$ heterojunction processes in skeletal distortions due to ion size differences due to Ga addition [39]. In the Ga atomic spectrum, peaks corresponding to $2 \mathrm{p}_{3 / 2}$ and $2 \mathrm{p}_{1 / 2}$ were observed at 1118.87 and $1145.80 \mathrm{eV}$, which corresponds to the Ga-S bond. On the other hand, three fitting curves were separated in the $\mathrm{S}$ atomic spectrum. The peak at low binding energy $(162.00 \mathrm{eV})$ corresponds to 
the $\mathrm{Cu}-\mathrm{S}$ bond, and the peak at the high binding energy $(165.28 \mathrm{eV})$ corresponds to the Ga-S bond [40]. Furthermore, the intermediate peak observed near $163.74 \mathrm{eV}$ corresponds to sulfur vacancy, which is attributed to sulfur defects formed at the $\mathrm{CuGaS}_{2}$ or heterojunction interface [41]. These XPS results demonstrate the presence of structural defects on the heterojunction $0.5 \mathrm{CuS} @ 1.5 \mathrm{CuGaS}$ catalyst surface and predict that the site can act as a reactive site.
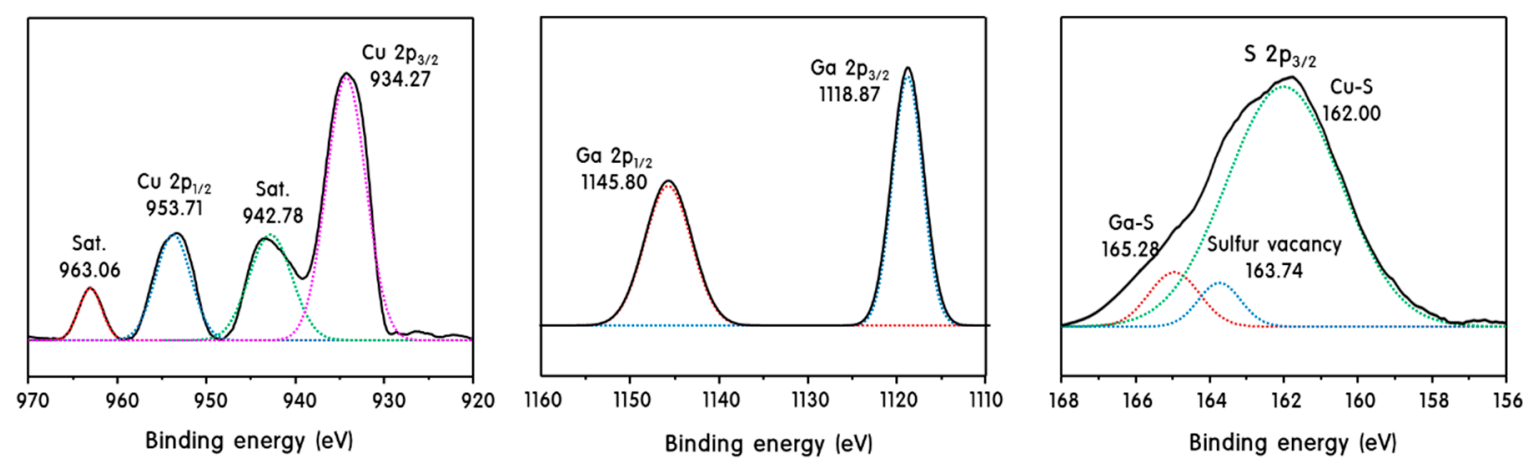

Figure 6. XPS spectra of heterojunction 0.5CuS@1.5CuGaS 2 catalysts.

Figure 7 summarizes the evolution of hydrogen from the photo splitting of aqueous methanol solution to $\mathrm{CuS}, \mathrm{CuGaS}_{2}$ and $\mathrm{CuS} @ \mathrm{CuGaS}_{2}$ catalysts. Figure 7A shows the amount of hydrogen generated under $365 \mathrm{~nm}$ UV light source conditions of the catalyst. The pure CuS catalyst showed little hydrogen evolution even after $10 \mathrm{~h}$ of reaction. On the other hand, the amount of hydrogen generation in the $\mathrm{CuGaS}_{2}$ catalyst was remarkably increased, and the amount of hydrogen produced after the reaction for $10 \mathrm{~h}$ reached $3000 \mu \mathrm{mol}$. In particular, the $\mathrm{CuS@CuGaS} 2$ and $0.5 \mathrm{CuS} @ 1.5 \mathrm{CuGaS} \mathrm{S}_{2}$ catalysts increased the amount of hydrogen generation further, reaching 3100 and $3250 \mu \mathrm{mol}$, respectively. Meanwhile, the heterojunction 1.5CuS@0.5 $\mathrm{CuGaS}_{2}$ catalyst with a high CuS ratio produced less hydrogen than $\mathrm{CuGaS}_{2}$. This is considered to be due to the fact that the portion exposed on the surface of the catalyst has a large amount of $\mathrm{CuS}$ and is less influenced by $\mathrm{CuGaS}_{2}$. According to the previous studies [42], the photo splitting process of methanol aqueous solution follows the following reaction:

$$
\begin{gathered}
\mathrm{CH}_{3} \mathrm{OH}+\mathrm{H}_{2} \mathrm{O} \rightarrow \mathrm{CO}_{2}+6 \mathrm{H}^{+}+6 \mathrm{e}^{-} \\
6 \mathrm{H}^{+}+6 \mathrm{e}^{-} \rightarrow 3 \mathrm{H}_{2} \\
\mathrm{CH}_{3} \mathrm{OH}+\mathrm{H}_{2} \mathrm{O} \rightarrow \mathrm{CO}_{2}+3 \mathrm{H}_{2}
\end{gathered}
$$

According to the above photolytic decomposition method of methanol, hydrogen and carbon dioxide are produced, but in this study, carbon dioxide was not observed because it exists as a $\mathrm{CO}_{2}$ ion in an aqueous solution. In addition, photolysis of methanol aqueous solution was further performed using a $150 \mathrm{~W}$ Xe lamp to confirm the catalytic activity in the visible region. The amount of hydrogen produced was reduced by about $1 / 20$ compared to the UV light source, and the $0.5 \mathrm{CuS} @ 1.5 \mathrm{CuGaS} 2$ catalyst, which was heterogeneously bonded to the $\mathrm{CuGaS}_{2}$ catalyst, produced about $200 \mu \mathrm{mol}$ of hydrogen. From these results, we have confirmed that $\mathrm{CuGaS}_{2}$ and the heterogeneous $\mathrm{CuS@CuGaS_{2 }}$ catalyst exhibit optical activity even in the visible region, albeit in a small amount compared to UV light sources.

From these results, we proposed an improved photocatalytic decomposition of aqueous solution of CuS@CuGaS 2 catalyst as shown in Scheme 1. The valence band, conduction band, and band gap values of $\mathrm{CuS}$ [18] and $\mathrm{CuGaS}_{2}$ [43] have already been reported in other studies and based on this, energy potential diagrams are shown together. In the heterojunction $\mathrm{CuS@CuGaS}$, the band gap of $\mathrm{CuGaS}_{2}$ contains $\mathrm{CuS}$, and $\mathrm{CuGaS}_{2}$ first acts as a light-absorbing agent. Electrons are excited from the valence band to the conduction band by light irradiation, and electrons generated from $\mathrm{CuGaS}_{2}$ can move to the conduction band of the adjacent CuS. This transfer is thermodynamically favorable 
by band gap alignment, and the photogenerated electrons react with $\mathrm{H}^{+}$to produce $\mathrm{H}_{2}$. At this time, $\mathrm{S}^{2-} / \mathrm{S}_{\mathrm{x}}{ }^{2-}$, which is a sacrifice material of the metal sulfide, captures holes by the following equation [44], and suppresses recombination between electron-hole pairs.

(1) $2 \mathrm{~S}^{2-}+2 \mathrm{~h}^{+} \rightarrow \mathrm{S}_{2}{ }^{2-}$

(2) $\mathrm{S}^{2-}+2 \mathrm{~h}^{+} \rightarrow \mathrm{S}$

A) Under UV light source $(365 \mathrm{~nm})$

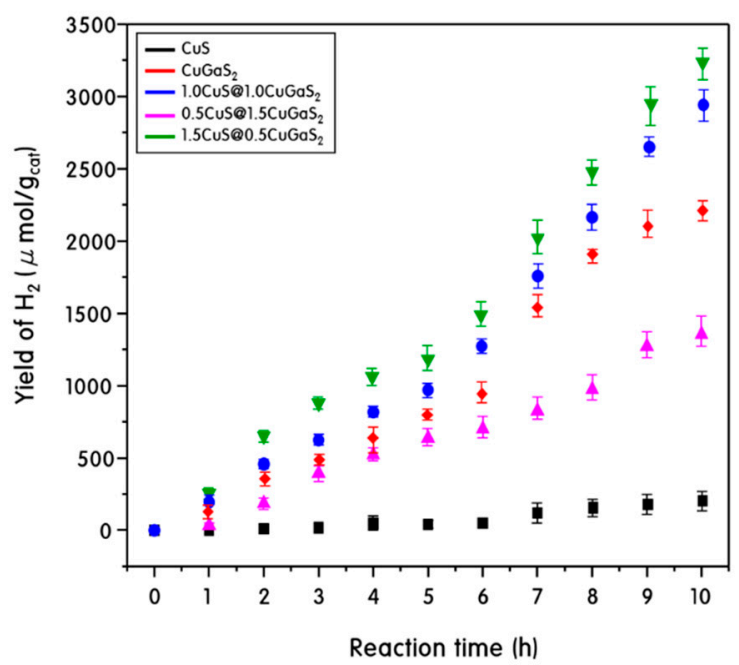

B) Under Visible light source (150W Xe lamp)

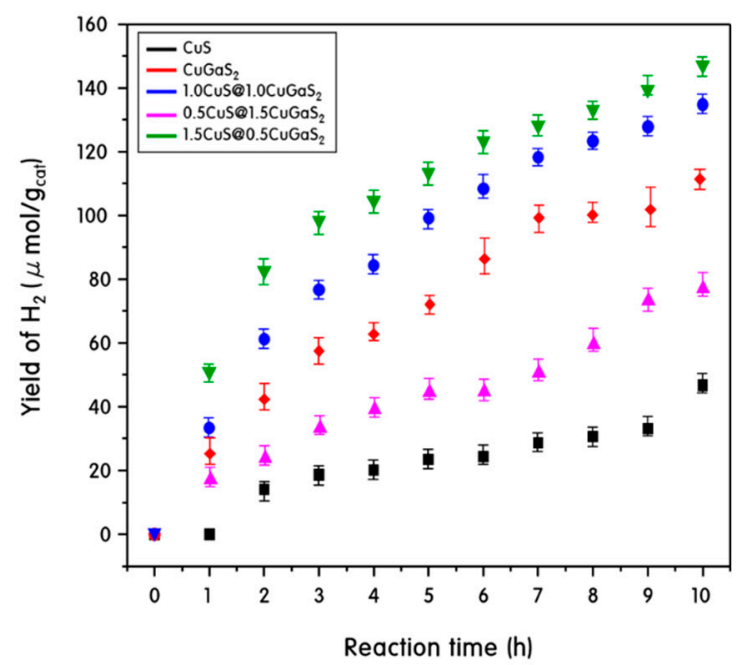

Figure 7. Evolution of $\mathrm{H}_{2}$ for methanol aqueous solution photo-splitting under UV light source (A) and visible light source (B) for $\mathrm{CuS}, \mathrm{CuGaS}_{2}$ and $\mathrm{CuS@CuGaS} 2$.
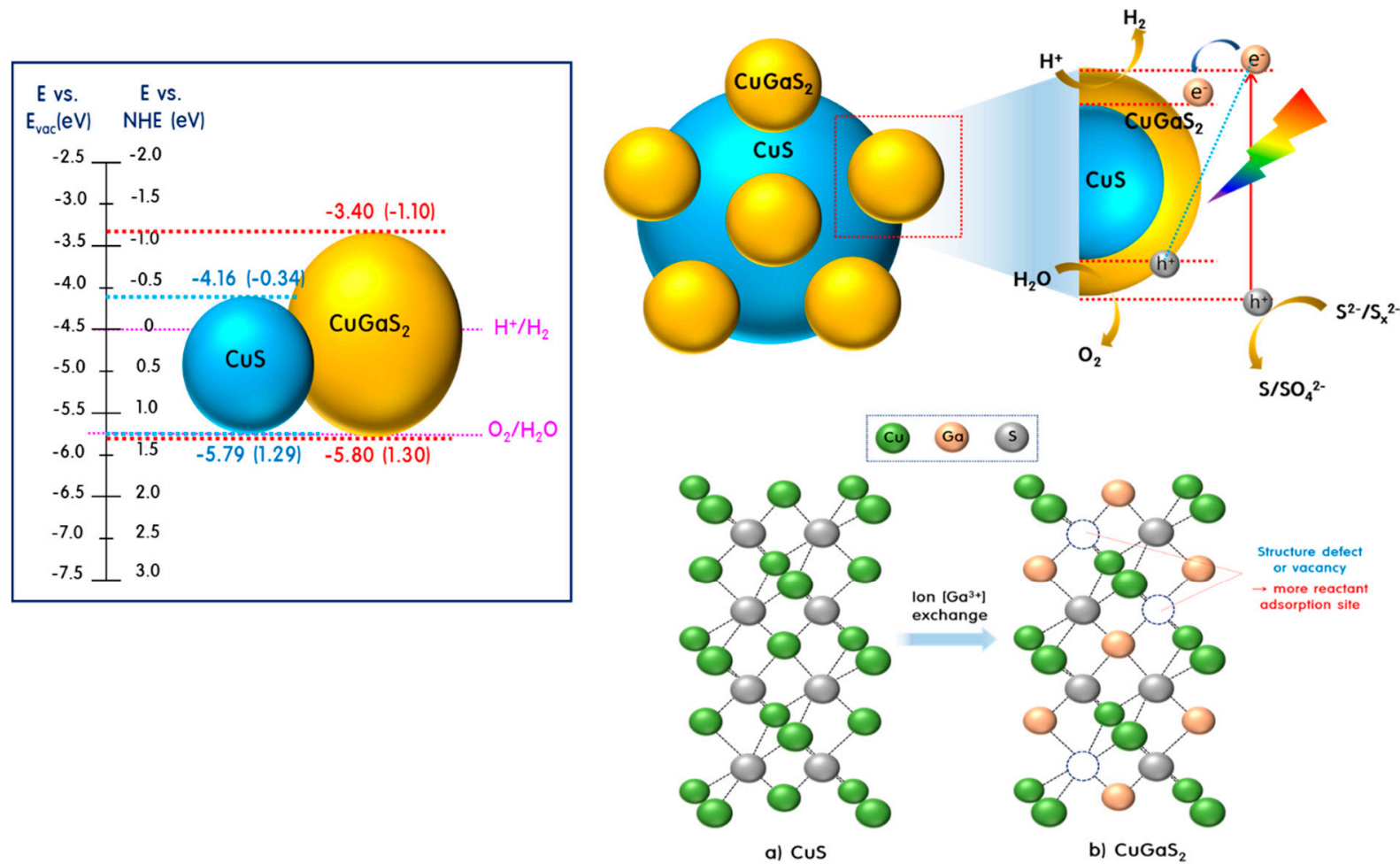

Scheme 1. The expected mechanism for methanol aqueous solution photo-splitting in photosystem with CuS@CuGaS 2 catalyst. 
In addition, structural defects of the $\mathrm{CuGaS}_{2}$ catalyst caused by the interface between the heterojunction CuS@CuGaS 2 catalyst and the $\mathrm{GaGaS}_{2}$ catalyst may act as a trap site to accelerate hole transfer and prolong the electron lifetime. In $\mathrm{CuGaS}_{2}$ structure, free electrons are gathered around $\mathrm{Ga}^{3+}$ for charge balance based on CuS structure, and sulfur vacancies due to structural defects are formed. These sites provide a place where the reactants can be adsorbed better, resulting in more products, and ultimately an improvement in photocatalytic activity. Moreover, structural defects at the CuS@CuGaS 2 catalyst interface form quasi-continuous energy levels and reduce ohmic contact to induce ohmic contact [28]. This contact recombines the holes formed in VB of CuS and the excited electrons in $\mathrm{CB}$ of $\mathrm{CuGaS}_{2}$, which ultimately promotes the efficiency of photocatalytic activity by promoting the separation efficiency of the photogenerated charge pair in the heterojunction CuS@CuGaS 2 complex catalyst.

\section{Experimental}

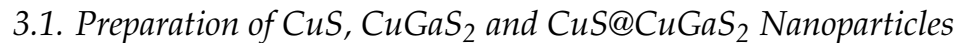

$\mathrm{CuS}$ and $\mathrm{CuGaS}_{2}$ nanoparticles were prepared using a typical sol-gel synthesis method [45]. Copper (II) nitrate trihydrate $\left(\mathrm{Cu}\left(\mathrm{NO}_{3}\right)_{2} \cdot 3 \mathrm{H}_{2} \mathrm{O}, 99.0 \%\right.$, Junsei Chemical, Tokyo, Japan), Gallium (III) nitrate hydrate $\left(\mathrm{Ga}\left(\mathrm{NO}_{3}\right)_{3} \cdot \times \mathrm{H}_{2} \mathrm{O}, 99.9 \%\right.$, Alfa Aesar, Tewksbury, MA, USA) and Thiourea $\left(\mathrm{CH}_{4} \mathrm{~N}_{2} \mathrm{~S}\right.$, 98.0\%, Junsei Chemical, Tokyo, Japan) were used as starting materials for $\mathrm{Cu}$, Ga and $\mathrm{S}$, respectively. First, in order to synthesize $\mathrm{CuS}, \mathrm{Cu}\left(\mathrm{NO}_{3}\right)_{2} \cdot 3 \mathrm{H}_{2} \mathrm{O}$ and $\mathrm{CH}_{4} \mathrm{~N}_{2} \mathrm{~S}$ were dissolved in ethylene glycol at a molar ratio of $1: 2$, mixed well and aged at $180{ }^{\circ} \mathrm{C}$ for $8 \mathrm{~h}$. The resulting powder was treated at $400{ }^{\circ} \mathrm{C}$ for $4 \mathrm{~h}$ under an argon atmosphere to obtain black $\mathrm{CuS}$ nanoparticles. In the synthesis of $\mathrm{CuGaS} 2$ particles, only the molar ratio of $\mathrm{Cu}\left(\mathrm{NO}_{3}\right)_{2} \cdot 3 \mathrm{H}_{2} \mathrm{O}, \mathrm{Ga}\left(\mathrm{NO}_{3}\right)_{3} \cdot \mathrm{H}_{2} \mathrm{O}$ and $\mathrm{CH}_{4} \mathrm{~N}_{2} \mathrm{~S}$ was changed to 1:1.25:4 during the synthesis of $\mathrm{CuS}$, respectively.

On the other hand, heterogeneous $\mathrm{CuS} @ \mathrm{CuGaS}_{2}$ nanoparticles were obtained by the impregnation method [46] using prepared $\mathrm{CuS}$ and $\mathrm{CuGaS}_{2}$. The synthesis procedure was as follows. The amounts of $\mathrm{CuS}$ and $\mathrm{CuGaS}_{2}$ added were different. CuS was added to ethanol, and the mixture was stirred for $2 \mathrm{~h}$, then $\mathrm{CuGaS}_{2}$ was added and stirred sufficiently. The homogeneously stirred solution was separated into powdery samples by centrifugation and dried at $80^{\circ} \mathrm{C}$ for $24 \mathrm{~h}$. Thereafter, the resultant was again annealed at $200^{\circ} \mathrm{C}$ for $2 \mathrm{~h}$ in order to remove impurities and increase the bonding strength, finally obtaining a heterogeneous $\mathrm{CuS@CuGaS} 2$ catalyst.

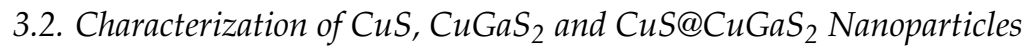

X-ray diffraction (XRD, MPD, PANalytical, Almelo, The Netherlands) was used to analyze the crystal structure of the prepared $\mathrm{CuS}, \mathrm{CuGaS}_{2}$ and heterojuntion $\mathrm{CuS} @ \mathrm{CuGaS}_{2}$ nanoparticles. XRD was measured at a $2 \theta$ angle of $20-100^{\circ}$ using nickel-filtered $\mathrm{CuK} \alpha(\lambda=1.5056 \AA)$ radiation $(40 \mathrm{kV}$, $30 \mathrm{~mA}$ ). The shape and size of the particles were confirmed using high-resolution transmission electron microscopy (TEM, H-7600, Hitachi, Tokyo, Japan) and scanning electron microscopy (SEM, S-4100, Hitachi, Tokyo, Japan). In addition, energy-dispersive X-ray spectroscope (EDS, EX-250, Horiba, Kyoto, Japan) analysis was used to identify the atomic composition of $\mathrm{CuS}, \mathrm{CuGaS}_{2}$, and heterogeneous $\mathrm{CuS@CuGaS} 2$ nanoparticles.

The diffuse reflection spectra of the particles were obtained using a UV-Vis spectrophotometer (Neosys-2000, SCINCO, Daejeon, Korea). The recombination tendency between the photogenerated electron-hole pair $\left(\mathrm{e}^{-} / \mathrm{h}^{+}\right)$of the catalyst was determined using a photoluminescence spectroscopy (PL, FS-2, SCINCO, Daejeon, Korea) equipped with a $150 \mathrm{~W}$ continuous Xenon lamp light source.

In addition, photocurrent and intensity modulated photovoltage spectroscopy (IMVS) measurements were taken with a two-electrode system to confirm the behavior of the photogenerated charge carrier. The catalyst was coated on fluorine doped tin oxide (FTO) glass to form a cell, and a platinum wire was used as a counter electrode. The catalyst coated on the FTO glass with a certain unit area was used as the working electrode and photocurrent was measured by irradiating light at intervals 
of $30 \mathrm{~s}$. The IMVS measurement was also performed using a visible light source in a two-electrode system, and the recombination lifetime of electrons was confirmed through the measurement.

\subsection{Hydrogen Production by Photo Splitting of Methanol Aqueous Solution Using CuS, CuGaS 2 and HeterojunctionCuS@CuGaS 2 Catalyst}

The photocatalytic decomposition of methanol aqueous solution was carried out using a liquid photoreactor prepared in our laboratory, which was reported in previous work [47]. First, the photocatalytic decomposition of methanol aqueous solution using a UV light source was performed using a pyrex reactor. $1.0 \mathrm{~L}$ of a mixed solution of $500 \mathrm{~mL}$ of methanol and $500 \mathrm{~mL}$ of distilled water was put into the reactor, and $0.5 \mathrm{~g}$ of the synthesized $\mathrm{CuS}, \mathrm{CuGaS}_{2}$ and $\mathrm{CuS@CuGaS}$ powder was added. Light was irradiated using a UV-lamp $\left(3 \times 6 \mathrm{~cm}^{-2}=18 \mathrm{~W} \mathrm{~cm}^{-2}\right.$, length $30 \mathrm{~cm}$, diameter $2.0 \mathrm{~cm}$, Shinan, Pochon, Korea) at a wavelength of $365 \mathrm{~nm}$ and the reaction was performed for a total of $10 \mathrm{~h}$. The photocatalytic decomposition of methanol aqueous solution using a visible light source was performed in a quartz reactor using a $150 \mathrm{~W}$ Xe lamp. The resulting gas was analyzed by gas chromatography (GC, DS7200, Donam Company, Gwangju, Korea) equipped with a thermal conductivity detector (TCD). The following GC conditions were used: TCD detector, Carboxen-1000 column (Bruker, Billerica, MA, USA), and the injection, oven and detector temperatures of 423, 393 and $473 \mathrm{~K}$, respectively.

\section{Conclusions}

We have synthesized $\mathrm{CuS}, \mathrm{CuGaS}_{2}$, and heterojunction $\mathrm{CuS@CuGaS}$ catalysts for hydrogen production through methanol aqueous photo splitting. The interface between the heterojunction CuS@CuGaS 2 catalyst and the structural defect of $\mathrm{CuGaS}_{2}$ formed by the addition of $\mathrm{Ga}^{3+}$ to $\mathrm{CuS}$ acted as a trap site. This trap site accelerates the electron-transfer, indicating a high photocurrent density value in the photocurrent results and excellent charge separation efficiency. In addition, compared to pure $\mathrm{CuS}$ and $\mathrm{CuGaS}_{2}$, as shown by photoluminescence and IMVS measurements, recombination between the excited electron-hole pairs in the heterojunction catalyst was suppressed, resulting in higher electron lifetime. As a result, the heterojunction $\mathrm{CuS} @ \mathrm{CuGaS}_{2}$ catalyst produced a significant amount of hydrogen gas, up to 3250 and $200 \mu \mathrm{mol}$, through photo splitting of aqueous methanol solution under UV and visible light irradiation, showing a significant increase in photocatalytic activity.

Author Contributions: Conceptualization, M.K.; Data curation, N.S. and J.Y.D.; Formal analysis, N.S. and J.Y.D.; Investigation, J.N.H. and Y.K.; Methodology, J.N.H. and Y.-S.Y.; Supervision, M.K.; Writing—original draft, J.Y.D.; Writing-review \& editing, M.K.

Funding: This work was supported by the National Research Foundation of Korea (NRF) grant funded by the Korean government (MSIT) (No. 2018R1A2B6004746).

Conflicts of Interest: The authors declare no conflict of interest.

\section{References}

1. Stam, W.; Gradmann, S.; Altantzis, T.; Ke, X.; Baldus, M.; Bals, S.; Donega, C. Shape Control of Colloidal $\mathrm{Cu}_{2-\mathrm{x}} \mathrm{S}$ Polyhedral Nanocrystals by Tuning the Nucleation Rates. Chem. Mater. 2016, 28, 6705-6715. [CrossRef] [PubMed]

2. Zhao, Y.; Burda, C. Development of plasmonic semiconductor nanomaterials with copper chalcogenides for a future with sustainable energy materials. Energy Environ. Sci. 2012, 5, 5564-5577. [CrossRef]

3. Sun, S.; Li, P.; Liang, S.; Yang, Z. Diversified copper sulfide $\left(\mathrm{Cu}_{2-\mathrm{x}} \mathrm{S}\right)$ micro /nanostructures: A comprehensive review on synthesis, modifications and applications. Nanoscale 2017, 9, 11357-11404. [CrossRef] [PubMed]

4. Tian, Q.; Hu, J.; Zhu, Y.; Zou, R.; Chen, Z.; Yang, S.; Li, R.; Su, Q.; Han, Y.; Liu, X. Sub-10 nm Fe $\mathrm{O}_{4} @ \mathrm{Cu}_{2}-\mathrm{xS}$ Core-Shell Nanoparticles for Dual-Modal Imaging and Photothermal Therapy. J. Am. Chem. Soc. 2013, 135, 8571-8577. [CrossRef] [PubMed]

5. Abdelhady, A.L.; Ramasamy, K.; Malik, M.A.; O’Brien, P.; Haigh, S.J.; Raftery, J. New routes to copper sulfide nanostructures and thin films. J. Mater. Chem. 2011, 21, 17888-17895. [CrossRef] 
6. Wang, N.; Gao, C.; Han, Y.; Huang, X.; Xu, Y.; Cao, X. Detection of human immunoglobulin G by label-free electrochemical immunoassay modified with ultralong CuS nanowires. J. Mater. Chem. B 2015, 3, 3254-3259. [CrossRef]

7. Li, Z.; Yang, H.; Ding, Y.; Xiong, Y.; Xie, Y. Solution-phase template approach for the synthesis of $\mathrm{Cu}_{2} \mathrm{~S}$ nanoribbons. Dalton Trans. 2006, 149-151. [CrossRef] [PubMed]

8. Yan, C.; Rosei, F. Hollow micro/nanostructured materials prepared by ion exchange synthesis and their potential applications. New J. Chem. 2014, 38, 1883-1904. [CrossRef]

9. Li, D.; Zheng, Z.; Lei, Y.; Ge, S.; Zhang, Y.; Zhang, Y.; Wong, K.W.; Yang, R.; Lau, W.M. Design and growth of dendritic $\mathrm{Cu}_{2}$-xSe and bunchy CuSe hierarchical crystalline aggregations. CrystEngComm 2010, 12, 1856-1861. [CrossRef]

10. Jayasekharan, T.; Gupta, S.L.; Dhiman, V. Binding of $\mathrm{Cu}^{+}$and $\mathrm{Cu}^{2+}$ with peptides: Peptides $=$ oxytocin, Arg8-vasopressin, bradykinin, angiotensin-I, substance-P, somatostatin, and neurotensin. J. Mass Spectrom. 2018, 53, 296-313. [CrossRef]

11. Sant, S.B. Nanoparticles: From Theory to Applications, Gunter Schmid, 2nd ed.; Wiley-VCH Verlag: Weinheim, Germany, 2010; ISBN 978-3-527-32589-4.

12. Saranya, M.; Santhosh, C.; Ramachandran, R.; Kollu, P.; Saravanan, P.; Vinoba, M.; Jeong, S.K.; Grace, A.N. Hydrothermal growth of CuS nanostructures and its photocatalytic properties. Powder Technol. 2014, 252, 25-32. [CrossRef]

13. Zhang, J.; Yu, J.; Zhang, Y.; Li, Q.; Gong, J.R. Visible light photocatalytic $\mathrm{H}_{2}$-production activity of CuS/ZnS porous nanosheets based on photoinduced interfacial charge transfer. Nano Lett. 2011, 11, 4774-4779. [CrossRef] [PubMed]

14. Lee, H.; Kwak, B.S.; Park, N.-K.; Baek, J.-I.; Ryu, H.-J.; Kang, M. Assembly of a check-patterned CuSx-TiO 2 film with an electron-rich pool and its application for the photoreduction of carbon dioxide to methane. Appl. Surf. Sci. 2017, 393, 385-396. [CrossRef]

15. Salak, A.N.; Ignatenko, O.V.; Zhaludkevich, A.L.; Lisenkov, A.D.; Starykeyich, M.; Zheludkevich, M.; Ferreira, M.G.S. High-pressure zinc oxysulphide phases in the ZnO-ZnS system. Phys. Status Solidi 2015, 212, 791-795. [CrossRef]

16. Yue, M.; Wang, R.; Ma, B.; Cong, R.; Gao, W.; Yang, T. Superior performance of CuInS 2 for photocatalytic water treatment: Full conversion of highly stable nitrate ions into harmless $\mathrm{N}_{2}$ under visible light. Catal. Sci. Technol. 2016, 6, 8300-8309. [CrossRef]

17. Han, F.; Kambala, V.S.R.; Srinivasan, M.; Jajarathnam, D.; Naidu, R. Tailored titanium dioxide photocatalysts for the degradation of organic dyes in wastewater treatment: A review. Appl. Catal. A 2009, 359, 25-40. [CrossRef]

18. Do, J.Y.; Chava, R.K.; Kim, S.K.; Nahm, K.; Park, N.-K.; Hong, J.-P.; Lee, S.J.; Kang, M. Fabrication of core@interface:shell structured CuS@CuInS $2: \mathrm{In}_{2} \mathrm{~S} 3$ particles for highly efficient solar hydrogen production. Appl. Surf. Sci. 2018, 451, 86-98. [CrossRef]

19. Chae, J.; Lee, J.; Jeong, J.H.; Kang, M. Hydrogen Production from Photo Splitting of Water Using the Ga-incorporated $\mathrm{TiO}_{2}$ s Prepared by a Solvothermal Method and Their Characteristics. Bull. Korean Chem. Soc. 2009, 30, 302-309.

20. Ravi, S.; Gopi, C.V.V.M.; Kim, H. Enhanced electrochemical capacitance of polyimidazole coated covellite CuS dispersed CNT composite materials for application in supercapacitors. Dalton Trans. 2016, 45, 12362-12372. [CrossRef]

21. Kundu, J.; Pradhan, D. Influence of precursor concentration, surfactant and temperature on the hydrothermal synthesis of CuS: Structural, thermal and optical properties. New J. Chem. 2013, 37, 1470-1479. [CrossRef]

22. Liu, S.; Nie, L.; Yuan, R. Growth, structure and optical characterization of $\mathrm{CuGaS}_{2}$ thin films obtained by spray pyrolysis. Chalcogenide Lett. 2015, 12, 111-116.

23. Kimi, M.; Yuliati, L.; Shamsuddin, M. Preparation of High Activity Ga and Cu Doped ZnS by Hydrothermal Method for Hydrogen Production under Visible Light Irradiation. J. Nanomater. 2015, 2015, 200. [CrossRef]

24. Scrivener, K.L.; Fullmann, T.; Galucci, E.; Walenta, G.; Bermejo, E. Quantitative study of Portland cement hydration by X-ray diffraction/Rietveld analysis and independent methods. Cem. Concr. Res. 2004, 34, 1541-1547. [CrossRef] 
25. Do, J.Y.; Lee, J.H.; Park, N.-K.; Lee, T.J.; Lee, S.T.; Kang, M. Synthesis and characterization of $\mathrm{Ni}_{2}-\mathrm{xPdxMnO} / / \gamma-\mathrm{Al}_{2} \mathrm{O}_{3}$ catalysts for hydrogen production via propane steam reforming. Chem. Eng. J. 2018, 334, 1668-1678. [CrossRef]

26. Lin, H.; Huang, C.P.; Li, W.; Ni, C.; Shah, I.; Tseng, Y.-H. Size dependency of nanocrystalline $\mathrm{TiO}_{2}$ on its optical property and photocatalytic reactivity exemplified by 2-chlorophenol. Appl. Catal. B. 2006, 68, 1-11. [CrossRef]

27. Huxter, V.M.; Mirkovic, T.; Nair, S.; Scholes, G.D. Demonstration of bulk semiconductor optical properties in processable $\mathrm{Ag}_{2} \mathrm{~S}$ and EuS nanocrystalline systems. Adv. Mater. 2008, 20, 2439-2443. [CrossRef]

28. Maeda, T.; Yu, Y.; Chen, Q.; Ueda, K.; Wada, T. Crystallographic and optical properties and band diagrams of $\mathrm{CuGaS}_{2}$ and $\mathrm{CuGa}_{5} \mathrm{~S}_{8}$ phases in $\mathrm{Cu}$-poor $\mathrm{Cu}_{2} \mathrm{~S}_{-} \mathrm{Ga}_{2} \mathrm{~S}_{3}$ pseudo-binary system. Jpn. J. Appl. Phys. 2017, 56, 04CS12. [CrossRef]

29. Aliaga, J.; Cifuentes, N.; González, G.; Sotomayor-Torres, C.; Benavente, E. Enhancement Photocatalytic Activity of the Heterojunction of Two-Dimensional Hybrid Semiconductors $\mathrm{ZnO} / \mathrm{V}_{2} \mathrm{O}_{5}$. Catalysts 2018, 8, 374. [CrossRef]

30. Tessler, N.; Rappaport, N. Excitation density dependence of photocurrent efficiency in low mobility semiconductors. J. Appl. Phys. 2004, 96, 1083-1087. [CrossRef]

31. Xiang, Q.; $\mathrm{Yu}$, J.; Jaroniec, $\mathrm{M}$. Enhanced photocatalytic $\mathrm{H}_{2}$-production activity of graphene-modified titania nanosheets. Nanoscale 2011, 3, 3670-3678. [CrossRef]

32. Djurišić, A.B.; Leung, Y.H.; Tam, K.H.; Ding, L.; Ge, W.K.; Chen, H.Y.; Gwo, S. Green, yellow, and orange defect emission from $\mathrm{ZnO}$ nanostructures: Influence of excitation wavelength. Appl. Phys. Lett. 2006, 88, 103107-103110. [CrossRef]

33. Yu, J.C.; Yu, J.; Ho, W.; Jiang, Z.; Zhang, L. Effects of $\mathrm{F}^{-}$Doping on the Photocatalytic Activity and Microstructures of Nanocrystalline $\mathrm{TiO}_{2}$ Powders. Chem. Mater. 2002, 14, 3808-3816. [CrossRef]

34. Mehmood, F.; Iqbal, J.; Ismail, M.; Mehmood, A. Ni doped $\mathrm{WO}_{3}$ nanoplates: An excellent photocatalyst and novel nanomaterial for enhanced anticancer activities. J. Alloy. Compd. 2018, 746, 729-738. [CrossRef]

35. Xie, Z.; Sui, Y.; Buckeridge, J.; Catlow, C.R.A.; Keal, T.W.; Sherwood, P.; Walsh, A.; Farrow, M.R.; Scanlon, D.O.; Woodley, S.M.; et al. Donor and Acceptor characteristics of Native Point Defects in GaN. arXiv, 2018; arXiv:1803.06273.

36. Cen, J.; Wu, Q.; Liu, M.; Orlov, A. Devloping new understanding of photo-electrochemical water splitting via in-situ techniques: A review on recent progress. Green Energy Environ. 2017, 2, 100-111. [CrossRef]

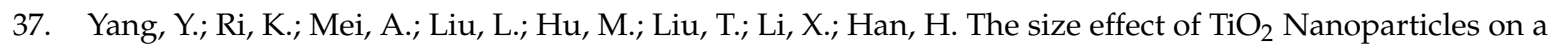
printable mesoscopic perovskite solar cell. J. Mater. Chem. A 2015, 3, 9103-9107. [CrossRef]

38. Bavarian, M.; Nejati, S.; Lau, K.K.S.; Lee, D.; Soroush, M. Theoretical and Experimental study of a Dye-Sensitized Solar Cell. Ind. Eng. Chem. Res. 2014, 53, 5234-5247. [CrossRef]

39. Ludwing, J.; An, L.; Pattengale, B.; Kong, Q.; Zhang, X.; Xi, P.; Huang, J. Ultrafast hole trapping and relaxation dynamics in p-type CuS nanodisks. J. Phys. Chem. Lett. 2015, 6, 2671-2675. [CrossRef] [PubMed]

40. Song, Y.; Li, Y.; Zhu, L.; Pan, Z.; Jiang, Y.; Wang, P.; Zhou, Y.-N.; Fang, F.; Hu, L.; Sun, D. CuGaS 2 nanoplates: A robust and self-healing anode for $\mathrm{Li} / \mathrm{Na}$ ion batteries in a wide temperature range of 268-318 K. J. Mater. Chem. A 2018, 6, 10886-11093. [CrossRef]

41. Dong, J.; Zeng, X.; Xia, W.; Zhang, X.; Zhou, M.; Wang, C. Ferromagnetic behavior of non-stoichiometric ZnS microspheres with a nanoplate-netted surface. RSC Adv. 2017, 7, 20874-20881. [CrossRef]

42. Do, J.Y.; Choi, S.; Nahm, K.; Kim, S.K.; Kang, M. Reliable hydrogen production from methanol photolysis in aqueous solution by a harmony between In and $\mathrm{Zn}$ in bimetallic zinc indium sulfide. Mater. Res. Bull. 2018, 100, 234-242. [CrossRef]

43. Cui, H.; Li, B.; Li, Z.; Li, X.; Xu, S. Z-scheme based CdS/CdWO 4 heterojunction visible light photocatalyst for dye degradation and hydrogen evolution. Appl. Surf. Sci. 2018, 455, 831-840. [CrossRef]

44. Kraeutler, B.; Bard, A.J. Heterogeneous Photocatalytic Decomposition of Saturated Carboxylic Acids on $\mathrm{TiO}_{2}$ Powder. Decarboxylative Route to Alkanes. J. Am. Chem. Soc. 1978, 100, 5985-5992. [CrossRef]

45. Peña-Garcia, R.; Guerra, Y.; Farias, B.V.M.; Martínez Buitrago, D.; Franco, A., Jr.; Padrón-Hernández, E. Effects of temperature and atomic disorder on the magnetic phase transitions in $\mathrm{ZnO}$ nanoparticles obtained by sol-gel method. Mater. Lett. 2018, 233, 146-148. 
46. Zhang, R.; Xu, J.; Lu, C.; Xu, Z. Photothermal application of $\mathrm{SmCoO}_{3} / \mathrm{SBA}-15$ catalysts synthesized by impregnation method. Mater. Lett. 2018, 228, 199-202. [CrossRef]

47. Son, N.; Do, J.Y.; Kang, M. Characterization of core@shell-structured ZnO@ $\mathrm{Sb}_{2} \mathrm{~S}_{3}$ particles for effective hydrogen production from water photo spitting. Ceram. Int. 2017, 43, 11250-11259. [CrossRef]

(c) 2019 by the authors. Licensee MDPI, Basel, Switzerland. This article is an open access article distributed under the terms and conditions of the Creative Commons Attribution (CC BY) license (http:/ / creativecommons.org/licenses/by/4.0/). 